\title{
Association of rs1219648 in FGFR2 and rs1042522 in TP53 with Premenopausal Breast Cancer in an Iranian Azeri Population
}

\author{
Zahra Saadatian ${ }^{1}$, Jalal Gharesouran ${ }^{2}$, Morteza Ghojazadeh ${ }^{2}$, Sahar Ghohari- \\ Lasaki $^{2}$, Najime Tarkesh-Esfahani ${ }^{3}$, Seyyed Mojtaba Mohaddes Ardebili ${ }^{1}$
}

\begin{abstract}
Breast cancer is the most common cancer among women in the world. In Iran, the incidence of breast cancer is on the increase. We here studied the association of rs1219648 in FGFR2 and rs1042522 in TP53 and their interaction in development of early onset sporadic breast cancer in Iranian Azeri population to evaluate epistatic effects on the risk of mammary neoplasia. We genotyped the two polymorphisms in 100 women with early onset breast cancer and 100 healthy women by PCR-RFLP. Allele frequency differences were tested using chi ${ }^{2}$-test with 95\% confident intervals. Our results indicated a statistically significant association $(p<0.05)$ between rs1219648, but not rs1042522, and risk of breast cancer. We also found that the combination of FGFR2 major genotype and TP53 hetero genotype had protective effects against breast cancer, while the hetero allele of $F G F R 2$ in combination with the minor genotype of TP53 was associated with a high risk. This study revealed an important crosstalk between two polymorphisms in FGFR2 and TP53 in development of breast cancer. These candidates risk variants should be further evaluated in studies with a larger sample size.
\end{abstract}

Keywords: Early onset breast cancer - FGFR2 - TP53 - Single nucleotide polymorphism

Asian Pac J Cancer Prev, 15 (18), 7955-7958

\section{Introduction}

Breast cancer is one of the most common diseases among women in the world with an incidence of more than 1000000 and death rate of 410000 in 2012 (Zhang et al., 2013). In Iran, it is also the most common cancer among women (Rahimzadeh et al., 2014). A number factors such as menopausal states and genetic variants can extend the risk of malignancy (Rai, 2014). Although breast cancer is frequent in postmenopausal women, the presentation of disease is high in premenopausal in undeveloped countries (Rai, 2014).

The role of genetic factors in development of breast cancer is well-documented (Han et al., 2011). Genomewide association studies have highlighted the role of single nucleotide polymorphisms in non-hereditary breast cancer susceptibility (Marian et al., 2011). As a result, fibroblast growth factor receptor 2 (FGFR2), a gene involved in mammary gland development, has been recognized as a prominent candidate in sporadic breast cancer (Sun et al., 2010; Tarkkonen et al., 2012). FGFR2 codes a transmembrane-type receptor involved in cellular functions (Cherdyntseva et al., 2012). Five single nucleotide polymorphisms (SNP) of FGFR2 gene are associated with breast cancer (Katoh, 2008). Among other SNPs, the role of rs1219648 (IVS2 $\pm 7033 \mathrm{~A}>\mathrm{G}$ ) in postmenopausal breast cancer is more remarkable (Hunter et al., 2007; Zhang et al., 2010a). Despite this clear evidence some researches stress on the effect of this polymorphism on premenopausal breast cancer $(\mathrm{Fu}$ et al., 2012). Genetic alterations of $F G F R 2$ cause aberrant activation of FGFR2 signaling in breast cancer (Katoh, 2008). Active FGFR2 mutants promote DNA-damage signaling and p53-dependent senescence (Ota et al., 2009). In addition it is proven that FGFR2 is sufficient to protect the cells from apoptosis (4) and apoptosis activation can induce by interaction between FGFR2 and TP53 (Ota et al., 2009). FGFR2 signaling increases the cytoplasmic level of mdm2 which can stop p53dependent apoptosis. So FGFR2 has epistatic effect on p53 (Shaulian et al., 1997; Hosokawa et al., 1998). TP53 gene encodes an antiancogenic homotetrameric protein that acts in control of cell cycle, DNA damage repairing and cell apoptosis (Denisov et al., 2012; Pouladi et al., 2014). $r s 1042522(\mathrm{Ex} 4 \pm 119 \mathrm{C}>\mathrm{G})$ is the most significant polymorphism, due to its function in the transactivation of the pro-apoptotic target genes of the p53 protein $(\mathrm{Li}$ et al., 2005; Khan et al., 2014). After that, the p53 P47S SNP may influence the risk and progression of cancer and the efficiency of therapy differently, depending on

${ }^{1}$ International Branch of Tabriz University of Medical Sciences (Aras), ${ }^{2}$ Department of Medical Genetics, Faculty of Medicine, Tabriz University of Medical Sciences, Tabriz, ${ }^{3}$ Department of Biostatistics, University of Social Welfare and Rehabilitation Sciences, Tehran, Iran*For correspondence: mohaddesmo@yahoo.com 
Zahra Saadatian et al

ethnic components (Al-Qasem et al., 2012). Namely, TP53 rs1042522 polymorphism inspires a protective effect to Mediterranean inhabitants against breast cancer ( $\mathrm{Hu}$ et al., 2010), but has a predisposing effect in Indians (He et al., 2011). In addition, crosstalk between the FGFR2 rs1219648 and TP53 rs1042522 in sporadic breast cancer has been demonstrated in Russian population by Cherdyntseva et.al (2012).

Based on above observations we decided to investigate the association of FGFR2 rs1219648 and TP53 rs1042522 polymorphisms with sporadic breast cancer in an Iranian Azeri population. Moreover, we estimated the cooperation of these polymorphisms for breast cancer modifications in both case and control groups.

\section{Materials and Methods}

\section{Samples}

In this case-control association study, samples included 100 women under 50, with the diagnosis of breast cancer and mean age of 39.32 years old, and 100 healthy women at same age range. All cases were without family history of breast cancer and were in premenopausal status and most of them have histological grade 2 tumors.

\section{DNA extraction and PCR}

Restriction fragment length polymorphism (RFLP) was our technique in this study. DNA extraction was carried out from blood lymphocytes using salting out protocol with proteinase $\mathrm{k}$ (Garner, 2000). The primer set used for rs1219648 amplification was: forward 5'-CACGCCTATTTTACTTGACACGC-3' and reverse, 5'-ATTTGTATGTGGTAGCTGACTTC-3'. Polymerase chain reaction was performed for this polymorphism with the following program: $94^{\circ} \mathrm{C}$ for $5 \mathrm{~min}, 94^{\circ} \mathrm{C}$ for 30 seconds, $58^{\circ} \mathrm{C}$ for $30 \mathrm{sec}, 72^{\circ} \mathrm{C}$ for $30 \mathrm{sec}, 72^{\circ} \mathrm{C}$ for 10 sec. The resulting $133 \mathrm{bp}$ bond was treated by APAF I and agarose gel (3\%) separated 109bp and 133bp fragments. The 24bp digestive fragment was invisible in agarose gel.

The primer set employed for amplification of segment encompassing rs 1042522 was 5'-CTGGTAAGGACAAGGGTTGG-3' as forward and 5'-ACTGACCGTGCAAGTCACAG-3' as reverse. A 396bp fragment was amplified and treated with BstuI restriction enzyme, producing two shorter fragments (231 and 165 bp long) on agarose gel (1\%). Each PCR reaction was accomplished in a total volume of $15 \mu \mathrm{l}$ containing 4ng genomic DNA, 6.25 mastermix red, 2.25 water and 1.25 from each primer.

\section{Statistical analysis}

The Chi-square test with 95\% confidence intervals was performed using SPSS v.17 software. p-value of less than 0.05 was considered as significant.

\section{Results}

\section{Single locus frequencies}

The distribution of TP53 rs1042522 and FGFR2 rs1219648 genotypes were in agreement with HW equibilirium $(\mathrm{p}>0.05)$.
As shown in Table 1, there was a remarkable association between rs1219648 and breast carcinogenesis $(\mathrm{p}<0.05)$ and according to table 2 the $\mathrm{G}$ allele of this polymorphism was strongly pronounced in breast cancer patients $(\mathrm{p}<0.05)(\mathrm{OR}=1.78$ [95\%CI: 1.174-2.699], $\mathrm{p}=0.006$ ). Extraordinarily and in contrast with previous investigation we didn't observe any association between rs1042522 polymorphism and breast cancer liability $(\mathrm{p}>0.05)$. However there was an association between heterozygote genotype and disease $(\mathrm{OR}=0.450$ [95\%CI: 0.206-0.984], $\mathrm{p}=0.043$ ).

\section{Genotype combination frequencies}

Rs1219648 and rs1042522 genotype incorporation handing out is presented in table 3 . The combination of rs1219648 AA genotype and rs1042522 GC genotype was protecting from breast cancer $(\mathrm{OR}=0.512$ [95\%CI: 0.263-0.997], $\mathrm{p}=0.047$ ) with the significant enlargement in healthy controls compared to the patients group. Also correlation of FGFR2 major allele with P53 minor allele presented the similar result powerfully $(\mathrm{OR}=0.279$ [95\%CI: 0.088-0.887], p=0.022). In contrast the FGFR2 AG in combination with TP53 GG \pm GC genotypes deviated from association. In spite of that, the significant enhancement in the proportion of rs 1219648 AG genotype

Table 1. FGFR2 rs1219648 are associated with breast cancer but $T P 53$ rs1042522 are Not

\begin{tabular}{llccc}
\hline & & Case & Control & $\mathrm{p}$ \\
\hline FGFR2 & Rs1219684 & 100 & 100 & 0.025 \\
Tp53 & Rs1042522 & 100 & 100 & 0.082 \\
\hline
\end{tabular}

Table 2. FGFR2 and TP53 Genotype Distribution in Breast Cancer Cases and Controls

\begin{tabular}{lrrlc}
\hline & Case & Control & $\mathrm{p}$ & OR $(95 \%)$ \\
\hline Rs1219648 allele & & & & \\
A & 117 & 143 & & \\
G & 83 & 57 & 0.006 & $1.78(1.174-2.699)$ \\
genotype & & & & \\
AA & 34 & 52 & 1 & \\
AG & 49 & 39 & 0.033 & $1.922(1.051-3.512)$ \\
GG & 17 & 9 & 0.02 & $2.889(1.156-7.222)$ \\
Rs1042522 allele & & & & \\
G & 92 & 89 & & \\
C & 108 & 111 & 0.763 & $0.941(0.635-1.396)$ \\
genotype & & & & \\
GG & 22 & 13 & 1 & \\
GC & 48 & 63 & 0.043 & $0.45(0.206-0.984)$ \\
CC & 30 & 24 & 0.495 & $0.739(0.309-1.764)$ \\
\hline
\end{tabular}

Table 3. FGFR2 and TP53 Genotype Combination Distribution in Breast Cancer Cases and Controls

\begin{tabular}{lcccc}
\hline & Case & Control & $\mathrm{p}$ & OR(95\%CI) \\
\hline Rs1219648 and rs1042522 & & & \\
AA and GG & 12 & 9 & 0.489 & \\
AA and GC & 18 & 30 & 0.047 & $0.512(0.263-0.997)$ \\
AA and CC & 4 & 13 & 0.022 & $0.279(0.088-0.887)$ \\
AG and GG & 5 & 3 & 0.47 & \\
AG and GC & 24 & 30 & 0.339 & \\
AG and CC & 20 & 6 & 0.003 & $3.917(1.5-10.227)$ \\
GG and GG & 5 & 1 & 0.097 & \\
GG and GC & 6 & 3 & 0.306 & \\
GG and CC & 6 & 5 & 0.756 & \\
\hline
\end{tabular}


combined with CC genotype of rs1042522 was shown in disease caring women compared with control subjects, proposing the importance of this combination in creation of breast tumors $(\mathrm{OR}=3.917$ [95\% CI:1.5-10.227], $\mathrm{p}=0.003)$. Other genotypes combination didn't show any association with disease.

\section{Discussion}

Breast cancer is one of the most common disorders in women worldwide (Long et al., 2013). Along with multifactorial, genetic background plays a well-established role in cancer etiology (Ayoub et al., 2011). Although a bulk of researches have revealed the role of genetic factors in breast cancer, currently the most of molecular basis of breast carcinogenesis remains unrecognized and conceivably tumor development can be as a result of corporation of genetic variants (Singh et al., 2008).

In the current study we investigated the association of rs1219648 and rs1042522 with breast malignancies separately; we evaluated the risk of early onset breast cancer in cooperation of these variants. Interestingly there was not any noticeable differences in distribution of allele frequencies of rs 1042522 or TP53 codon 72 polymorphism in both case and control groups. However a considerable association was noticed about rs1219648 polymorphism.

Many authors have reported a significant association between rs1219648 and postmenopausal breast cancer (Liang et al., 2008; Raskin et al., 2008; Prentice et al., 2009; Jia et al., 2010). In a genome wide association study, Hunter and his colleagues found a significant association between rs1219648 and postmenopausal breast cancer $(\mathrm{p}<0.01)$ too (Hunter et al., 2007). However, limited researches have been done on the impact of rs1219648 on early onset breast cancer. Although the recent study by Chun-Lian Liu and coworkers has been refused the impact of rs1219648 in premenopausal breast cancer (Liu et al., 2013), in another investigation carried out on Chines Han woman a great association appeared between rs1219648 and premenopausal breast cancer (Fu et al., 2012). In our study the association between the $\mathrm{G}$ allele of rs 1219648 FGFR2 and early onset breast cancer is in agreement with the aforementioned study ( $\mathrm{p}=0.006)$. In addition, it is most likely that $G$ allele carriers may display a high breast cancer risk and this observation asserts that the role of $\mathrm{G}$ allele is considerable in predisposing malignancy than protective effect of A allele in heterozygote's. In contrast to many studies (Papadakis et al., 2000; Buyru et al., 2003; Zhuo et al., 2009; Zhang et al., 2010b), we did not observe any association between the TP53 codon 72 polymorphism and breast cancer risk. In Cherdyntseva et al work the C allele of the TP53 gene was significantly linked with an increased cancer risk among young Russian women (Cherdyntseva et al., 2012). According to Abeer AlQasem et al the $\mathrm{G}$ allele increases the risk of breast cancer (Al-Qasem et al., 2012). Doosti and his colleagues have also confirmed this finding (Doosti et al., 2011). Unlike aforementioned studies, some investigations confirm us (Suspitsin et al., 2003). For instance, Khadang et al didn't observe a significant association between polymorphic alleles of rs 1042522 and breast cancer liability (Khadang et al., 2007).

Gene-gene interaction or epistasis is considered as an indispensable component of the genetic factors in multifactorial diseases (Turner and Bush, 2011). Not long past investigation revealed the contribution of cancerrelated FGFR2 mutants with p53 in the installation of DNA-damage signaling and senescence in primary human cells (Ota et al., 2009). Furthermore FGFR2 activated by bfgf ligand multiply amounts of $\mathrm{mdm} 2$ and causes obstruction of p53 dependent apoptosis (Shaulian et al., 1997). In the current study we found FGFR2 and TP53 gene variants corporations in breast cancer development. A similar study had been done by Cherdyntseva et al. in Russian population (Cherdyntseva et al., 2012). Their results showed the association of FGFR2 AG and TP53 rs1042522 GC \pm CC genotypes with premenopausal breast cancer liability (OR=2.04[95\%CI: 1.14-3.63], $\mathrm{p}=0.015)$. Furthermore their study showed the protective effect of the major allele of $F G F R 2$ in combination with major allele of P53 (OR=0.28[95\%CI: 0.13-0.63], p=0.003). However this effect was not seen in our population; we observed the AG genotype of rs1219648 in combination with CC genotype of rs1042522 TP53 significantly elevates the risk of breast cancer $(\mathrm{OR}=30917$ [95\%CI: 1.5-10.227], $\mathrm{p}=0.003$ ), whereas AA genotype of $F G F R 2$ with $\mathrm{GC} \pm \mathrm{CC}$ genotype of TP53 have a protective effect on cancer development (OR=0.512[95\%CI: 0.263-0.997], $\mathrm{p}=0.047)$ and $(\mathrm{OR}=0.279[95 \% \mathrm{CI}: 0.088-0.887], \mathrm{p}=0.022)$.

Regrettably, the number of samples was low in this study and the clinical characteristics of some patients were out of reach. Thereupon we couldn't scrutiny these polymorphisms in relation to some clinical characteristics and this could explain the differentiation between current study and previous studies.

In conclusion, findings of the present study have shown the concerning role of $\mathrm{G}$ allele of FGFR2 rs1219648 in early onset sporadic breast cancer susceptibility in Iranian Azeri population. Whereas the rs 1042522 polymorphism has no impact on breast cancer in this population, there is a significant association between TP53 and FGFR2 polymorphisms genotype combinations.

\section{References}

Al-Qasem A, Toulimat M, Tulbah A, et al (2012). The p53 codon 72 polymorphism is associated with risk and early onset of breast cancer among Saudi women. Oncol Lett, 3, 875-8.

Ayoub N, Lucas C, Kaddoumi A (2011). Genomics and pharmacogenomics of breast cancer: current knowledge and trends. Asian Pac J Cancer Prev, 12, 1127-40.

Buyru N, Tigli H, Dalay N (2003). P53 codon 72 polymorphism in breast cancer. Oncol Rep, 10, 711-4.

Cherdyntseva NV, Denisov EV, Litviakov NV, et al (2012). Crosstalk between the FGFR2 and TP53 genes in breast cancer: data from an association study and epistatic interaction analysis. DNA Cell Biol, 31, 306-16.

Denisov EV, Cherdyntseva NV, Litviakov NV, et al (2012). TP53 gene polymorphisms in cancer risk: the modulating effect of ageing, ethnicity and TP53 somatic abnormalities. In 'Tumor Suppressor Genes', Eds Intech, 79-110.

Doosti A, Ghasemi-Dehkordi P, Davoudi N (2011). p53 codon72 polymorphism associated with breast cancer in Iranian 
patients. African J Pharmacy Pharmacol, 5, 1278-81.

Fu F, Wang C, Huang M, et al (2012). Polymorphisms in second intron of the FGFR2 gene are associated with the risk of early-onset breast cancer in Chinese Han women. Tohoku J Exp Med, 226, 221-9.

Garner I (2000). The Nucleic Acid Protocols Handbook. In Eds Humana Press, 3-7.

Han W, Woo JH, Yu JH, et al (2011). Common genetic variants associated with breast cancer in Korean women and differential susceptibility according to intrinsic subtype. Cancer Epidemiol Biomarkers Prev, 20, 793-8.

He XF, Su J, Zhang Y, et al (2011). Association between the p53 polymorphisms and breast cancer risk: meta-analysis based on case-control study. Breast Cancer Res Treat, 130, 517-29.

Hosokawa K, Aharoni D, Dantes A, et al (1998). Modulation of $\mathrm{Mdm} 2$ expression and $\mathrm{p} 53$-induced apoptosis in immortalized human ovarian granulosa cells. Endocrinology, 139, 4688-700.

Hu Z, Li X, Yuan R, et al (2010). Three common TP53 polymorphisms in susceptibility to breast cancer, evidence from meta-analysis. Breast Cancer Res Treat, 120, 705-14.

Hunter DJ, Kraft P, Jacobs KB, et al (2007). A genome-wide association study identifies alleles in FGFR2 associated with risk of sporadic postmenopausal breast cancer. Nat Genet, 39, 870-4.

Jia C, Cai Y, Ma Y, et al (2010). Quantitative assessment of the effect of FGFR2 gene polymorphism on the risk of breast cancer. Breast Cancer Res Treat, 124, 521-8.

Katoh M (2008). Cancer genomics and genetics of FGFR2 (Review). Int J Oncol, 33, 233-7.

Khadang B, Fattahi MJ, Talei A, et al (2007). Polymorphism of TP53 codon 72 showed no association with breast cancer in Iranian women. Cancer Genet Cytogenet, 173, 38-42.

Khan MH, Rashid H, Mansoor Q, et al (2014). Association of the rs 1042522 polymorphism with increased risk of prostate adenocarcinoma in the Pakistani population and its HuGE review. Asian Pac J Cancer Prev, 15, 3973-80.

Li X, Dumont P, Della Pietra A, et al (2005). The codon 47 polymorphism in p53 is functionally significant. $\mathrm{J} \mathrm{Biol}$ Chem, 280, 24245-51.

Liang J, Chen P, Hu Z, et al (2008). Genetic variants in fibroblast growth factor receptor 2 (FGFR2) contribute to susceptibility of breast cancer in Chinese women. Carcinogenesis, 29, 2341-6.

Liu CL, Hu XP, Guo WD, et al (2013). Case-control study on the fibroblast growth factor receptor 2 gene polymorphisms associated with breast cancer in Chinese Han women. $J$ Breast Cancer, 16, 366-71.

Long J, Zhang B, Signorello LB, et al (2013). Evaluating genome-wide association study-identified breast cancer risk variants in African-American women. PLoS One, 8, 58350.

Marian C, Ochs-Balcom HM, Nie J, et al (2011). FGFR2 intronic SNPs and breast cancer risk: associations with tumor characteristics and interactions with exogenous exposures and other known breast cancer risk factors. Int J Cancer, 129, 702-12.

Ota S, Zhou ZQ, Link JM, et al (2009). The role of senescence and prosurvival signaling in controlling the oncogenic activity of $F G F R 2$ mutants associated with cancer and birth defects. Hum Mol Genet, 18, 2609-21.

Papadakis EN, Dokianakis DN, Spandidos DA (2000). p53 codon 72 polymorphism as a risk factor in the development of breast cancer. Mol Cell Biol Res Commun, 3, 389-92.

Pouladi N, Kouhsari SM, Feizi MH, et al (2014). Lack of association of intron 316 bp polymorphism of TP53 with breast cancer among Iranian-Azeri patients. Asian Pac J Cancer Prev, 15, 2631-4.
Prentice RL, Huang Y, Hinds DA, et al (2009). Variation in the FGFR2 gene and the effects of postmenopausal hormone therapy on invasive breast cancer. Cancer Epidemiol Biomarkers Prev, 18, 3079-85.

Rahimzadeh M, Baghestani AR, Gohari MR, et al (2014). Estimation of the cure rate in Iranian breast cancer patients. Asian Pac J Cancer Prev, 15, 4839-42.

Rai V (2014). The methylenetetrahydrofolate reductase C677T polymorphism and breast cancer risk in asian populations. Asian Pac J Cancer Prev, 15, 5853-60.

Raskin L, Pinchev M, Arad C, et al (2008). FGFR2 is a breast cancer susceptibility gene in jewish and arab israeli populations. Cancer Epidemiol Biomarkers Prev, 17, 1060-5.

Shaulian E, Resnitzky D, Shifman O, et al (1997). Induction of Mdm2 and enhancement of cell survival by bFGF. Oncogene, 15, 2717-25.

Singh V, Rastogi N, Mathur N, et al (2008). Association of polymorphism in MDM-2 and p53 genes with breast cancer risk in Indian women. Ann Epidemiol, 18, 48-57.

Sun C, Olopade OI, Di Rienzo A (2010). rs2981582 is associated with FGFR2 expression in normal breast. Cancer Genet Cytogenet, 197, 193-4.

Suspitsin EN, Buslov KG, Grigoriev MY, et al (2003). Evidence against involvement of $\mathrm{p} 53$ polymorphism in breast cancer predisposition. Int J Cancer, 103, 431-3.

Tarkkonen KM, Nilsson EM, Kahkonen TE, et al (2012). Differential roles of fibroblast growth factor receptors (FGFR) 1, 2 and 3 in the regulation of S115 breast cancer cell growth. PLoS One, 7, 49970.

Turner SD, Bush WS (2011). Multivariate analysis of regulatory SNPs: empowering personal genomics by considering cisepistasis and heterogeneity. Pac Symp Biocomput, 276-87.

Zhang J, Qiu LX, Wang ZH, et al (2010a). Current evidence on the relationship between three polymorphisms in the FGFR2 gene and breast cancer risk: a meta-analysis. Breast Cancer Res Treat, 124, 419-24.

Zhang YX, Wang XM, Kang S, et al (2013). Common variants in the PALB2 gene confer susceptibility to breast cancer: a meta-analysis. Asian Pac J Cancer Prev, 14, 7149-54.

Zhang Z, Wang M, Wu D, et al (2010b). P53 codon 72 polymorphism contributes to breast cancer risk: a metaanalysis based on 39 case-control studies. Breast Cancer Res Treat, 120, 509-17.

Zhuo W, Zhang Y, Xiang Z, et al (2009). Polymorphisms of TP53 codon 72 with breast carcinoma risk: evidence from 12226 cases and 10782 controls. J Exp Clin Cancer Res, 28, 115. 